\title{
Identifying Perceptions and Preferences of the General Public Concerning Universal Screening of Children for Familial Hypercholesterolaemia
}

\author{
Faye L. Bowman ${ }^{a}$ Caron M. Molster ${ }^{a}$ Karla J. Lister ${ }^{a} \quad$ Alicia T. Bauskis $^{a}$ \\ Jacquie Garton-Smith ${ }^{b}$ Alistair W. Vickery ${ }^{c}$ Gerald F. Watts ${ }^{c, d}$ \\ Andrew C. Martin ${ }^{e, f}$
}

a Office of Population Health Genomics, Public and Aboriginal Health Division, Western Australian Department of Health, East Perth, WA, Australia; ${ }^{b}$ Health Networks, Clinical Excellence Division, Western Australian Department of Health, East Perth, WA, Australia; ' $S$ Chool of Medicine, Faculty of Health and Medical Sciences, University of Western Australia, Crawley, WA, Australia; ${ }^{d}$ Lipid Disorders Clinic, Cardiometabolic Service, Department of Cardiology, Royal Perth Hospital, Perth, WA, Australia; 'Department of General Paediatrics, Perth Children's Hospital, Perth, WA, Australia; ${ }^{f}$ School of Paediatrics and Child Health, Faculty of Health and Medical Sciences, University of Western Australia, Crawley, WA, Australia

\section{Keywords}

Familial hypercholesterolaemia - Universal screening of children · Public acceptability · Public perspectives . Deliberation

\begin{abstract}
Background/Aims: Familial hypercholesterolaemia $(\mathrm{FH})$ is a common genetic disorder that, if untreated, predisposes individuals to premature coronary heart disease. As most individuals with $\mathrm{FH}$ remain undiagnosed, new approaches to detection are needed and should be considered a priority in public health genomics. Universal screening of children for FH has been proposed, and this study explores public perspectives on the acceptability of this approach. Methods: A one-day deliberative public forum was held in Perth, WA, Australia. Thirty randomly selected individuals were recruit-
\end{abstract}

ed, with self-reported sociodemographic characteristics used to obtain discursive representation. Participants were presented with information from a variety of perspectives and asked to discuss the information provided to identify points of consensus and disagreement. The data collected were analysed using thematic analysis. Results: Of the 17 participants at the forum, 16 deemed universal screening of children for $\mathrm{FH}$ to be acceptable. Fifteen of these 16 believed this was best performed at the time of an immunisation. Participants proposed a number of conditions that should be met to reduce the likelihood of unintended harm resulting from the screening process. Discussion/Conclusion: The outcomes of the forum suggest that establishing a universal screening programme for $\mathrm{FH}$ in childhood is acceptable to the general public in WA.

(c) 2019 The Author(s) Published by S. Karger AG, Basel

\begin{tabular}{ll}
\hline KARGER & $\begin{array}{l}\text { @ } 2019 \text { The Author(s) } \\
\text { Published by S. Karger AG, Basel }\end{array}$ \\
E-Mail karger@karger.com & $\begin{array}{l}\text { Karger } \\
\text { This article is licensed under the Creative Commons Attribution- }\end{array}$ \\
www.karger.com/phg & $\begin{array}{l}\text { NonCommercial-NoDerivatives 4.0 International License (CC BY- } \\
\text { NC-ND) (http://www.karger.com/Services/OpenAccessLicense). } \\
\text { Usage and distribution for commercial purposes as well as any dis- } \\
\text { tribution of modified material requires written permission. }\end{array}$
\end{tabular}

Faye Bowman

Western Australian Department of Health, Office of Population Health Genomics 189 Royal Street

East Perth, WA 6004 (Australia)

E-Mail faye.bowman@ health.wa.gov.au 


\section{Introduction}

Advances in genomics have led to a significant improvement in our understanding of how genes and the environment interact to influence health. This increased understanding of the genetic determinants of health has been coupled with recognition of their potential application to improve health at a population level [1-3]. However, with the exception of newborn bloodspot screening, examples of how developments in this field have been translated into public health practice are limited $[1,4-6]$. This is particularly the case when it comes to common, complex conditions, such as heart disease.

One reason for the translation gap in public health genomics for more common conditions is that in genomic studies, most of the genetic variants that have been identified as contributing to common diseases are only associated with small increases in relative risk and explain only a little about the relationship between these diseases and genetic inheritance [5, 7-9]. Another reason for the translation gap is that while tools and techniques based on genomic knowledge have been developed, there has often been a lack of evidence regarding their validity and utility, largely due to the complexity of conducting such evaluations $[1,2,8]$. Despite these challenges, there are several examples of genomic applications where evidence supports their implementation into public health practice. One of these, which can be considered to be a priority for public health genomics [10], is the use of populationbased approaches to detect individuals with the condition familial hypercholesterolaemia (FH).

$\mathrm{FH}$ is an autosomal dominant genetic disorder, and the most common and serious disorder of cholesterol metabolism. It is estimated to affect around one in every 250 people [11-14]. In Australia, this rate equates to almost 100,000 people thought to be living with $\mathrm{FH} \mathrm{[15].} \mathrm{FH} \mathrm{is}$ characterised by markedly elevated levels of low-density lipoprotein cholesterol (LDL-C) from birth [14, 16-18]. When untreated, this results in accelerated atherosclerosis and a 100-fold increase in the risk of mortality from coronary heart disease (CHD) between the ages of 20 and 40 years [19]. However, individuals who are diagnosed and treated from a young age are anticipated to have a normal life expectancy [20]. Statins are highly effective in reducing LDL-C levels and significantly decrease the health risks associated with $\mathrm{FH}$. However, despite major advances in knowledge of the condition, FH remains largely undetected and untreated worldwide, with more than $90 \%$ of individuals unaware they have the condition $[12,18,21,22]$.
The most cost-effective approach for identifying cases of FH is cascade screening [23-27]. Under this approach, new ("index") cases of FH are detected via active case finding, generally following a heart attack or diagnosis of heart disease. A cholesterol test, with or without DNA analysis, can then be offered to at-risk genetic relatives to identify whether these family members also have FH. However, in most countries around the world - with the exception of the Netherlands - cascade screening has had limited effectiveness, and thus the majority of individuals with FH remain undetected. This is because cascade screening is reliant upon the identification of a sufficient number of independent index cases, otherwise detection will be limited to a small number of families $[28,29]$. For example, a state-wide cascade screening programme was established in Western Australia (WA) in 2007. Despite progress being made, only $10.5 \%$ of individuals estimated to be living with the condition, including $3.5 \%$ of children and adolescents, have been diagnosed to date [pers. commun., Dr. Jing Pang, December 2017]. These very low rates of FH detection are similar to those in other developed countries [12, 18, 21, 22].

One possible approach to increasing detection rates for FH is the establishment of a universal screening programme, which would complement the cascade screening approach. Under a universal screening programme, all individuals in a defined population would be offered a blood test to measure LDL-C and/or total cholesterol levels. Those with cholesterol levels above a defined cut-off level, and thus at greatest risk of $\mathrm{FH}$, could then be referred for a confirmatory diagnostic assessment, which may include DNA analysis. In addition to the direct benefits of universal screening for $\mathrm{FH}$ associated with increased detection rates, individuals diagnosed with $\mathrm{FH}$ through the programme would also represent new index cases, thereby supporting a more effective and comprehensive cascade screening approach to identify other family members with FH.

While beneficial at any age, offering universal screening during childhood would maximise the potential to detect, diagnose and treat individuals with the condition before atherosclerosis has become established [30]. Early childhood (ages 1-9 years) is the optimal period for using LDL-C levels to discriminate between individuals with and without $\mathrm{FH}$ in the general population $[12,14,31]$. Furthermore, it is recommended that statins are commenced in children with $\mathrm{FH}$ from the age of 8-10 years [14]. To date, only one country (Slovenia [32]) has implemented a universal screening approach; however, the effectiveness of this programme is as yet uncertain.
Bowman/Molster/Lister/Bauskis/ Garton-Smith/Vickery/Watts/Martin 
Before establishing a universal screening programme, such as for $\mathrm{FH}$, the appropriateness of doing so must first be determined by considering the associated range of benefits, harms and ethical issues in full. The Wilson and Jungner screening principles [33], developed for the World Health Organisation in 1968, have traditionally been used to determine whether a screening programme should be established. These principles relate to the characteristics of the condition, accuracy and effectiveness of the screening test, availability of treatment, and parameters of the intended screening programme. In 2008, the Wilson and Jungner screening principles were reviewed to consider their applicability in the context of genetic screening [34]. The revised criteria that stemmed from this review reflect the need for population-level policy decisions to be based not just on high-quality evidence and contextual considerations, but also on the values of the population.

Engaging with the public is a critical step in implementing public health genomics initiatives, particularly given the significant ethical, legal and social concerns associated with screening for genetic conditions $[35,36]$. Doing so can help identify and articulate the values of the community and align policy recommendations with these expectations [37]. By promoting credibility and trust through the transparency of processes, it can also help to make policies more likely to be implemented as intended and accepted by the public [37].

In a previous pilot study of universal screening of children for FH [38], more than $90 \%$ of parents stated they would screen a second child for $\mathrm{FH}$ at 1-2 years of age if screening was routinely offered. In a larger follow-up study, more than $80 \%$ of parents of 13,000 children invited to participate in a universal screening study [13] accepted the offer of screening, suggesting the approach of universal screening of children for FH was acceptable to the vast majority of families. However, no studies have been published thus far that fully explore the perceived benefits and harms of universal screening for $\mathrm{FH}$ from the public perspective. Addressing this knowledge gap would assist governments in reaching an informed decision as to whether screening children for FH is appropriate. In line with this goal, the current study presents outcomes from a public forum that aimed to explore the perspectives of the public on the acceptability of screening children for $\mathrm{FH}$ in WA. In conducting this study, the researchers aimed to answer two questions, being:

1 What do members of the general public perceive to be the potential benefits and harms of screening children for $\mathrm{FH}$ ?

Public Preferences Concerning Screening Children for Familial
2 Do members of the general public perceive screening children for FH to be acceptable? If so, at what age should children be screened for $\mathrm{FH}$, and is it acceptable for this to be done at the same time as immunisation?

\section{Materials and Methods}

A 1-day deliberative public forum was held in February 2016, in Perth, WA, Australia. Deliberative methods are qualitative approaches that have been advocated when citizen input is being sought for policy issues that are complex, value-laden and have contested ethical dimensions, where diverse perspectives exist on the public interests of the issues and where there is low public awareness of these perspectives [39-41]. Such approaches have been used to explore citizen perspectives of a range of health-related issues [42-46] including population-based screening [47-50]. Therefore, these deliberative methods are appropriate for exploring the issue of population-based screening of children for FH.

\section{Recruitment}

To recruit participants to attend the forum, 600 telephone numbers, names and residential addresses were randomly selected from an electronic version of the 2013 Western Australian telephone directory. This information was then provided to an accredited market research agency that undertook the recruitment on behalf of the researchers. The intention was for approximately 20 members of the general public to attend the forum, which deliberative theorists claim is around the maximum size for a group to enable genuine deliberation [51]. With this in mind, the market research agency was asked to recruit 30 people, with the presumption that not all would attend the forum.

Sociodemographic characteristics were used as proxy measures to obtain "discursive representation" among forum attendees [40, 52]. This differs from "proportional representation" in that instead of aiming for a statistically representative sample, which is recognised to be nearly impossible to achieve [45], the goal is to obtain a broad range of perspectives held by members of the general public. As such, quotas were applied (see Table 1, under "Results"), so that a minimum number of participants was achieved for characteristics that may be relevant to the issue of universal screening of children for FH. Namely, the random sample was stratified by selfreported sex (male or female), age (18-44, 45-64 or 65+ years), indigenous status, highest education level (non-university or university), geographic location (metropolitan or non-metropolitan), first language (English or non-English), parental status and previous diagnosis of high cholesterol or heart disease. Attendees were offered AUD 150 to reimburse them for expenses associated with their attendance. To facilitate equity of access to the forum, those living outside the metropolitan area were offered additional reimbursement if required, to assist with travel and accommodation costs.

The market research agency successfully recruited a cohort of 30 people meeting the defined quotas. An information package was sent to all recruits containing an introductory letter inviting them to attend the forum, a participant information sheet and a consent form seeking written consent to participate (online suppl. material Appendices 1-3; for all online suppl. material, see www.karger.

Public Health Genomics 2019;22:25-35 
com/doi/10.1159/000501463). The participant information sheet provided an overview of why the public forum was being held and outlined that all individuals' details and responses would be deidentified and remain confidential. It gave general information about the purpose of the forum and about $\mathrm{FH}$, without providing too much information that might bias the deliberations at the forum. The information package was followed up with a telephone call by the researchers to discuss the information provided, to offer an opportunity for the potential recruit to ask any questions, and to receive verbal confirmation that the information was understood. Recruits were then asked to complete and sign the consent form and return it in a reply-paid envelope to the forum organisers.

\section{Forum Design}

The deliberative public forum incorporated design features that distinguish deliberative approaches from other types of public engagement. Specifically, the forum, facilitated by an individual who was independent of the WA public health care system, was designed to explicitly identify shared citizen values and determine what decisions informed citizens may reach on this specific policy issue $[51,53-55]$. This was achieved by presenting attendees with opportunities to learn about and reflect on a range of perspectives relating to universal screening of children for $\mathrm{FH}$, using the process outlined below.

Approximately 2 weeks before the forum, the recruits were mailed a booklet that provided introductory information on cholesterol, FH, how FH is diagnosed and treated, universal screening, some arguments for and against screening children for $\mathrm{FH}$, the purpose and design of the public forum, and what tasks the attendees would be asked to do on the day (online suppl. material Appendix 4). The booklet was informed by an extensive literature review, with input and editorial feedback received from experts in $\mathrm{FH}$, screening and public consultation. Participants were asked to read the booklet and consider the information it provided ahead of attending the forum.

In the section of the booklet providing information on universal screening, two options were proposed for when screening children for FH may best occur. These were (1) at the age of 8-10 years, when statin treatment for managing $\mathrm{FH}$ is recommended to commence or (2) at the same time as one of the childhood immunisations. Screening at the time of childhood immunisation was outlined as being able to occur at either the age of 4 years, with the pre-school booster, or the age of 12-13 years, with the year 8 human papillomavirus vaccine. These options were used to guide discussions at the forum regarding the age at which screening should occur, should universal screening be deemed acceptable.

The forum itself was structured into two sessions. The first session comprised a series of six short presentations, approximately 15 min each, during which participants were encouraged to take notes and ask questions. The presentations were delivered by a government policy maker, a paediatrician, a parent of a child with $\mathrm{FH}$, a young adult with $\mathrm{FH}$, a general practitioner and an ethicist. The presenters largely focused on what they perceived to be the potential benefits and harms of universal screening in general, and of screening children for FH specifically, and the perceived alternatives to such screening.

The forum's second session comprised deliberation by participants. Participants were first given some time alone to reflect on the information presented during the first session. Then, in small groups of five to six people, participants were asked to respectfully listen to and reason with each other about the perceived benefits and harms/risks of universal screening for FH. They then discussed whether they felt universal screening of children for $\mathrm{FH}$ was acceptable, and if so, at what time. Key points of discussion were recorded by the group on feedback sheets and were reported back to the whole group. This was followed by a facilitated whole-ofgroup discussion where the group collectively identified points of consensus and disagreement across the small group decisions, both of which were legitimate outcomes of this process of decisionmaking [52]. Consensus was reached through dialogue that enabled participants to reason with each other about the arguments for and against each position, followed by negotiation to achieve a common position [45].

\section{Data Analysis}

The data collected were analysed using thematic analysis, which was undertaken by three of the researchers. Each analyst independently read through the feedback sheets that contained summaries of the small group discussions and the whole group decisions, including where consensus was reached and areas of persistent disagreement. The researchers then coded the data into themes, before coming together to collaboratively work through the identified themes to reach a final agreed position.

\section{Results}

\section{Participant Characteristics}

Table 1 presents the characteristics of recruited members of the general public and the 17 participants who attended the forum.

\section{Perceived Benefits and Harms of Screening Children for $\mathrm{FH}$}

Potential benefits and harms of screening children for FH that were identified by participants are summarised in Table 2. The perceived benefits related to: improved wellbeing of children diagnosed with $\mathrm{FH}$ as a result of participating in the screening programme; the flow-on direct and indirect benefits for the family of that child, such as opportunities for cascade screening and reproductive choice; building community knowledge and awareness, and opportunities for population-level data collection and analysis; and efficiencies for the health system. Potential harms that were identified related to: the direct impact of the screening programme on the child participating in a screening programme for $\mathrm{FH}$, including potential psychological impacts and the possibility of experiencing disadvantage (such as increased insurance premiums) as a result of a diagnosis of $\mathrm{FH}$; broader impacts on the family of that child, such as the financial burden of ongoing treatment and the potential for questions around paternity; the costs and burden on the health system of running a uni- 
Table 1. Minimum quotas for recruitment, number of people recruited and the final number of attending participants, by characteristic

\begin{tabular}{|c|c|c|c|}
\hline Characteristics & $\begin{array}{l}\text { Minimum } \\
\text { quota }\end{array}$ & Recruited & Participants \\
\hline \multicolumn{4}{|l|}{ Sex } \\
\hline Male & 7 & 11 & 6 \\
\hline Female & - & 19 & 11 \\
\hline \multicolumn{4}{|l|}{ Age group } \\
\hline $16-44$ years & 5 & 13 & 8 \\
\hline $45-64$ years & 5 & 8 & 4 \\
\hline $65+$ years & 5 & 9 & 5 \\
\hline \multicolumn{4}{|c|}{$\begin{array}{l}\text { Identify as an indigenous } \\
\text { Australian }\end{array}$} \\
\hline No & - & 29 & 16 \\
\hline Yes & 1 & 1 & 1 \\
\hline \multicolumn{4}{|c|}{ Highest education achieved } \\
\hline Non-university & 10 & 19 & 12 \\
\hline University & 5 & 11 & 5 \\
\hline \multicolumn{4}{|l|}{ Location } \\
\hline Metropolitan & - & 24 & 12 \\
\hline Non-metropolitan & 4 & 6 & 5 \\
\hline \multicolumn{4}{|l|}{$\begin{array}{l}\text { Non-English-speaking } \\
\text { background }\end{array}$} \\
\hline No & - & 19 & 11 \\
\hline Yes & 1 & 11 & 6 \\
\hline \multicolumn{4}{|l|}{ Parent } \\
\hline No & 7 & 11 & 8 \\
\hline Yes & 7 & 19 & 9 \\
\hline \multicolumn{4}{|c|}{ History of high cholesterol } \\
\hline No & - & 24 & 14 \\
\hline Yes & 2 & 6 & 3 \\
\hline \multicolumn{4}{|l|}{ History of heart disease } \\
\hline No & - & 28 & 15 \\
\hline Yes & 2 & 2 & 2 \\
\hline
\end{tabular}

versal screening programme; questions around the accuracy of the screening test and possibility for overdiagnosis; and potential impacts of long-term treatment with statins.

\section{Acceptability of Screening Children for $\mathrm{FH}$}

Having considered the identified benefits and harms of screening for $\mathrm{FH}$, all but one participant agreed that in principle, the benefits of screening outweighed the harms and therefore screening children for FH was acceptable. For some participants, while they agreed screening to be beneficial, there were conditions that needed to be met in order for them to consider screening to be acceptable. These included: participation in the screening programme is voluntary; consent must be obtained from parents prior to a child being screened; there should be a specialist involved with detailed knowledge of $\mathrm{FH}$, as op- posed to a GP who participants feared might not have indepth knowledge of the condition; there is choice about whether to take statins or not; there are "clear, standardised clinical pathways"; participants are made aware that the screening test is a cholesterol test and not a genetic test, and there are guidelines around when genetic testing would be undertaken. One participant felt that the benefits did not outweigh the harms and consequently that screening children for $\mathrm{FH}$ is not acceptable.

\section{Acceptability of Screening at the Same Time as Childhood Immunisation}

Fifteen out of 17 participants agreed that screening children for FH at the same time as they undergo an immunisation is acceptable. The reasons given by participants for this decision included:

- No additional/multiple doctor visits would be required, therefore screening at the time of immunisation is easy and convenient for parents

- It would increase the uptake of screening relative to a stand-alone screening programme

- There would be a lower cost for screening by "piggy backing" on immunisation

- Conscientious objectors to immunisation are more likely to be objectors to FH screening as well, so it would not be an issue if they miss out (however, they should still be given the option of participating in screening for $\mathrm{FH}$ )

Two people did not agree that screening children for $\mathrm{FH}$ at the same time as immunisation is acceptable. This included the one participant who did not find screening for FH itself acceptable, and in addition did not support immunisation. The other participant, who did not express opposition to immunisation, gave the following reasons for their point of view:

- Not everyone gets their children immunised and these children would miss out on FH screening

- Immunisations are traumatic enough on their own

- It would be an extra reason for parents to opt out of immunisation

- It would be best to screen at around the time that statins can be taken as a treatment (i.e., between 8 and 10 years) but there are no immunisation programmes delivered during this age period

\section{Age at Which Screening of Children Should Occur}

Of the 16 participants who found screening of children for FH acceptable, 13 agreed that screening should occur at 4 years of age, for the following reasons:

- Parents can make early adjustments to a healthy lifestyle for the whole family 
Table 2. Perceived benefits and harms of universal screening of children for FH reported by forum participants

\begin{tabular}{|c|c|}
\hline Benefits & Harms \\
\hline \multicolumn{2}{|l|}{ Screening participant } \\
\hline $\begin{array}{l}\text { Supports earlier detection of FH, leading to knowledge of personal FH } \\
\text { status and immediate benefits such as opportunities for earlier } \\
\text { treatment; an early diagnosis could be "good motivation to do the right } \\
\text { thing" in terms of adopting healthier dietary and lifestyle behaviours }\end{array}$ & $\begin{array}{l}\text { Psychological impacts may be associated with receiving a diagnosis of } \mathrm{FH} \text {, } \\
\text { such as feeling distressed due to a positive result, anxiety about their } \\
\text { increased chance of suffering a heart attack or stroke, or differential } \\
\text { treatment by their family because of their worry about the future }\end{array}$ \\
\hline $\begin{array}{l}\text { Enables children to live longer, healthier lives, and have the ability to } \\
\text { reach their full life potential in terms of their career, contribution to } \\
\text { society and support for their family }\end{array}$ & $\begin{array}{l}\text { Individuals may experience "disadvantage" due to the disclosure of a } \\
\text { diagnosis of FH; for example, declaring a genetic condition may affect } \\
\text { career prospects or insurance premiums }\end{array}$ \\
\hline $\begin{array}{l}\text { As screening participants get older, knowledge of their FH status can } \\
\text { bring "peace of mind" and enable reproductive choices }\end{array}$ & Temporary physical discomfort when undergoing the test \\
\hline \multicolumn{2}{|l|}{ Family } \\
\hline $\begin{array}{l}\text { Could "put other family members on high alert for FH" and enables } \\
\text { opportunities for cascade screening }\end{array}$ & $\begin{array}{l}\text { Financial "drain" of ongoing treatment and management of the condition } \\
\text { due to the "expensive" drugs required to treat FH }\end{array}$ \\
\hline $\begin{array}{l}\text { Potentially reduces "family trauma," such as death or incapacitation of } \\
\text { a family member because of a preventable cardiovascular event }\end{array}$ & $\begin{array}{l}\text { A diagnosis of FH may impact family relationships, such as cascade } \\
\text { screening leading to implications regarding paternity, or a child feeling } \\
\text { "alienated" if they are the only family member with the condition }\end{array}$ \\
\hline Supports reproductive choice for parents & No further harms to the family identified \\
\hline Potentially increases family bonding due to shared experience & \\
\hline
\end{tabular}

\section{Community}

Increases community knowledge and awareness of $\mathrm{FH}$, which could lead to a "snowball effect" with more people choosing to be tested for the condition

Increases community awareness, which could lead to the

"normalisation" of FH; this could result in reduced psychological effects of being diagnosed with the condition, and less discrimination, stigma and assumptions such as the condition being a result of eating "too much crappy food"

Possible flow-on benefits of positive lifestyle changes among family, friends of those affected and the community in general

Supports collection and analysis of long-term data regarding the management of individuals and their family members; this could lead to increased knowledge of $\mathrm{FH}$ and investment by industry into further research

\section{Health care system}

The screening test is more accurate in children, and the condition is easy to treat and manage; screening during childhood is therefore the most efficient approach for the health care system

There may be cost savings to, and reduced burden on, the health system through prevention of associated health problems that require hospitalisation (e.g., heart attacks and strokes)

No further benefits to the health care system identified
No harms to the community identified

High costs are associated with establishing, running and monitoring a screening programme; this money may "be better spent on conditions affecting more people or directed towards better health spent in general including education"

Requires the education of health professionals

Requires the provision of counselling services following a positive diagnosis

Expected effectiveness and efficiency of screening may not be realised (e.g., if families/children do not comply with prescribed treatment)

May impact on participation rates for immunisation programmes if $\mathrm{FH}$ is screened at the same time

\section{Screening test}

No benefits associated with the screening test identified

Questions exist regarding the appropriateness of cut-off levels for detecting $\mathrm{FH}$ (e.g., false positives and false negatives); more research is required

Increased public awareness could lead to panic and overdiagnosis 
Table 2. (continued)

Treatment

No benefits directly attributed to treatment were identified; however, benefits associated with treatment were implied in perspectives such as: children identified with FH have access to earlier treatment and can lead longer, healthier lives; family trauma could potentially be reduced through avoidance of preventable cardiovascular events; and there may be cost savings to the health system through the prevention of health problems associated with $\mathrm{FH}$ that would require hospitalisation
Existing low knowledge of $\mathrm{FH}$ by health professionals may result in inappropriate prescriptions of statins

People diagnosed with the condition may "hide behind" treatment and would not make lifestyle changes

Parents may feel obligated to treat their children with statins

There are some known side effects associated with statin use in the short term

The long-term side effects of treating children with statins are unknown; more research is required

Only one drug is known to be effective at treating $\mathrm{FH}$; there was concern this may lead to a "market monopoly" and that the "push" for screening may be coming from the pharmaceutical company manufacturing statins
- It enables earlier cascade screening of other family members

- The test is most accurate at this time, thereby providing the highest chance of detecting $\mathrm{FH}$

- Screening at this time is cost-effective

- Children do not have "barriers up," meaning they have less fear of needles and blood collection

One participant believed screening of children for $\mathrm{FH}$ should occur at 1 year of age because this would allow interventions to commence earlier, and they held the belief that lifelong dietary preferences are set between the ages of 1 and 4 years. Another participant felt screening should occur between 8 and 10 years through "active recruitment" by GPs and practice nurses, whereby children would opportunistically be offered a screening test when they attend a medical centre for other reasons, because this is "still early enough to make lifestyle changes required and at the age when children could start treatment if needed." This participant also believed that being screened at this age would be less traumatic for the child than doing it at an earlier age. Finally, one participant was in favour of screening at 12-13 years because they held concerns regarding treatment with statins during childhood and its associated side effects.

\section{Discussion/Conclusion}

Overall, this study suggests that the WA general public deems universal screening of children for $\mathrm{FH}$ to be acceptable. To the authors' knowledge, this is the first study to establish public acceptability of universal screening of children for FH. This finding is important for governments considering universal screening for $\mathrm{FH}$, because it demonstrates that conducting further work to assess the effectiveness and appropriateness of establishing such a programme may be warranted.

At the forum, participants identified a range of benefits and harms associated with universal screening for $\mathrm{FH}$. The benefits and harms that were identified are largely in line with those that have been described in clinical studies and guidelines. Specifically, previously cited potential benefits of universal screening for $\mathrm{FH}$ primarily relate to: early detection of $\mathrm{FH}$; supporting the commencement of management approaches to minimise irreversible damage due to atherosclerosis; increasing the detection rate of index cases, which enables cascade screening of family members; and the availability of a simple, non-fasting blood cholesterol test to detect children at increased risk of FH [14, 56-58]. Potential harms cited in the literature include: questions around test accuracy; the lack of longterm data regarding the side effects of statin use from childhood; detection of mild or benign forms of FH; and the acceptability, practicability and cost-effectiveness of this approach $[14,18,59-61]$. In addition to these possible harms, a number of ethical issues associated with universal screening for FH have been raised in the literature, such as insurance implications associated with a diagnosis due to the increased risk of heart disease [62] and possible unearthing of misattributed paternity as a result of cascade screening [11]. Of relevance is also the established ethical issue for universal screening of children being the child's right not to know, given the parent is pro- 
viding consent on their behalf [63]. The identification of the majority of these benefits, harms and ethical issues by forum participants illustrates that their decision-making was based on a thorough consideration of the potential impacts of universal screening of children for $\mathrm{FH}$.

The policy implications of this study are that the public are likely to support the establishment of a universal screening programme, which is a key criterion for assessing the appropriateness of establishing a government screening programme [33, 64]. However, in applying these findings, it should be noted that decision-makers must also consider other criteria when considering the appropriateness of establishing such a programme. For example, an assessment of appropriateness would need to involve the detailed consideration of evidence relating to the attributes of the condition, screening test, treatment and requirements of the screening programme, in line with the Wilson and Jungner screening principles [33] and, in Australia, the Population Based Screening Framework [64]. Doing so would enable the benefits and harms of screening to be considered in full, thereby supporting an evidence-based decision as to whether a universal screening programme for FH should be established.

Furthermore, an assessment of appropriateness should consider whether a universal screening programme is the most efficient public health approach for increasing diagnosis rates for $\mathrm{FH}$ and decreasing the burden of $\mathrm{CHD}$. Opportunistic approaches for identifying new cases of FH through WA's cascade screening programme have not resulted in a marked improvement in detection rates to date. However, the education and training of GPs and other relevant health care providers may be an alternative to establishing a universal screening programme, by improving the detection rate of $\mathrm{FH}$ in primary care.

In 2011, an Expert Panel for the National Heart, Lung, and Blood Institute released cardiovascular risk reduction guidelines, recommending universal lipid screening between the ages of 9 and 11 years, and again between 17 and 21 years [58], by paediatricians. This represents an opportunistic approach to the identification of index cases. The release of these guidelines, in conjunction with educational initiatives and electronic health record modifications, has recently been found to be correlated with an increase in paediatric lipid screening [56]. This suggests that raising awareness of $\mathrm{FH}$ through public health approaches such as education, supported by an appropriate policy, may be an effective approach to increasing diagnosis rates for FH. Further research to explore this alternative and contrast its effectiveness to universal screening of children is recommended.
Also of note for decision-makers is the potential harm identified by participants that the expected effectiveness and efficiency of universal screening for $\mathrm{FH}$ may not be achieved if individuals diagnosed with $\mathrm{FH}$ do not adhere to their prescribed treatment. This harm warrants particular consideration given that many of the benefits of universal screening for $\mathrm{FH}$ are built on the assumption that diagnosis leads to effective treatment.

One of the strengths of this research is the deliberative methodology that was used. This approach to obtaining citizen input to public policy is deemed particularly suitable when the policy issue in question, in this case universal screening of children, involves "democratic deficits," which include "contested ethical issues, competing public interests and low public awareness of perspectives held in relation to the issues" [45]. Using the deliberative method enabled trade-offs in perspectives to be identified and the identification of shared public values, which should underpin public policy in a pluralist society.

A key limitation of this study is that the members of the public who participated represent a small sample of the population. Specifically, while the public forum was appropriately sized for public deliberation, the outcomes represent the views of only 17 individuals. It is recommended that further research is conducted to consolidate the findings of this study. This could be achieved through a larger population survey that further explores the identified issues and outcomes. It is also worth noting that at the time this study was undertaken, the study by Wald et al. [13] had not yet been published, so screening children at 1-2 years of age was not offered as an option to participants.

An important finding of this study that warrants further examination is that in reaching a decision, the public emphasised the potential lifestyle and community benefits of establishing a screening programme for $\mathrm{FH}$. For example, participants focused on the concept that an early diagnosis could lead to the adoption of healthier dietary and lifestyle behaviours by the affected individual, the family and friends of those affected, and the community in general. However, research has demonstrated that perceptions of disease risk have limited influence on behaviour [65]. For example, communicating an individual's genetic risk for common complex diseases appears to have little or no effect on adopting risk-reducing behaviour [66]. Further research is recommended to explore how a diagnosis of FH impacts health attitudes and lifestyle behaviours, particularly for an individual and their family.

Heart disease is a key public health issue in Australia and internationally. Evidence supports the implementa-
Bowman/Molster/Lister/Bauskis/ Garton-Smith/Vickery/Watts/Martin 
tion of public health approaches to increase detection rates for $\mathrm{FH}$ as a priority for public health genomics. Universal screening of children may be an effective option to support early detection of and intervention for $\mathrm{FH}$, thereby reducing morbidity and mortality associated with the condition, and consequently with CHD, in the community. This study is the first to present evidence on the acceptability to the public of such an approach. Further research is recommended to consolidate this finding and provide further evidence on the effectiveness of universal FH screening. More work is also recommended to determine the most appropriate age at which screening should be offered, given the tension between the age at which the screening test for $\mathrm{FH}$ is most accurate, and questions around the point at which treatment for the condition can be safely commenced. Such advances in knowledge are essential in order to support policy makers in developing appropriate strategies to address the significant public health issue of CHD.

\section{Acknowledgement}

We would like to acknowledge the contributions of the participants and presenters at the forum and thank them for their time and valued input. A.C.M. is supported by a Raine Medical Research Foundation Clinician Research Fellowship.

\section{Statement of Ethics}

All attendees at the public forum provided written informed consent to participate. Ethics approval was provided by Princess Margaret Hospital's Human Research Ethics Committee.

\section{Disclosure Statement}

The authors have no conflicts of interest to declare.

\section{Funding Sources}

This research project was funded through a grant from the Princess Margaret Hospital (now Perth Children's Hospital) Foundation. The Foundation had no role in the preparation of data or the manuscript.

\section{Author Contributions}

All authors critically revised the manuscript for important intellectual content and provided final approval for the paper to be published.

F.L.B. provided substantial contributions to the design of the study, interpretation of the data and the first draft of the manuscript.

C.M.M. provided substantial contributions to the conception and design of the study, the collection, analysis and interpretation of data, and the first draft of the manuscript.

K.J.L. provided substantial contributions to the conception and design of the study, and the collection, analysis and interpretation of data.

A.T.B. provided substantial contributions to the design of the study and the collection, analysis and interpretation of data.

J.G.-S. provided substantial contributions to the conception and design of the study.

A.W.V. and G.F.W. provided substantial contributions to the conception and design of the study, and the collection of data.

A.C.M. provided substantial contributions to the conception and design of the study, and the collection and interpretation of data.

\section{References}

1 Bowen MS, Kolor K, Dotson WD, Ned RM, Khoury MJ. Public health action in genomics is now needed beyond newborn screening. Public Health Genomics. 2012;15(6):327-34.

2 McGrath BB. Advancing the post-genomic era agenda: contributions from public health. Public Health Genomics. 2012;15(3-4):12531.

3 Molster CM, Bowman FL, Bilkey GA, Cho AS, Burns BL, Nowak KJ, et al. The evolution of public health genomics: exploring its past, present, and future. Front Public Health. 2018 Sep; $6: 247$

4 Boccia S, Mc Kee M, Adany R, Boffetta P, Burton $\mathrm{H}$, Cambon-Thomsen A, et al. Beyond public health genomics: proposals from an international working group. Eur J Public Health. 2014 Dec;24(6):877-9.
5 Burke W, Atkins D, Gwinn M, Guttmacher A, Haddow J, Lau J, et al. Genetic test evaluation: information needs of clinicians, policy makers, and the public. Am J Epidemiol. 2002 Aug; 156(4):311-8.

6 Khoury MJ, Gwinn M, Yoon PW, Dowling N, Moore CA, Bradley L. The continuum of translation research in genomic medicine: how can we accelerate the appropriate integration of human genome discoveries into health care and disease prevention? Genet Med. 2007 Oct;9(10):665-74.

7 El-Sayed AM, Koenen KC, Galea S. Rethinking our public health genetics research paradigm. Am J Public Health. 2013 Oct;103 Suppl 1:S14-8.
8 Boccia S, Brand A, Brand H, Ricciardi G. The integration of genome-based information for common diseases into health policy and healthcare as a major challenge for Public Health Genomics: the example of the methylenetetrahydrofolate reductase gene in noncancer diseases. Mutat Res. 2009 Jul;667(1-2): 27-34.

9 Khoury MJ, Bowen MS, Clyne M, Dotson WD, Gwinn ML, Green RF, et al. From public health genomics to precision public health: a 20-year journey. Genet Med. 2018 Jun;20(6): $574-82$.

10 Aarden E, Van Hoyweghen I, Horstman K The paradox of public health genomics: definition and diagnosis of familial hypercholesterolaemia in three European countries. Scand J Public Health. 2011 Aug;39(6):634-9. 
11 Nordestgaard BG, Chapman MJ, Humphries SE, Ginsberg HN, Masana L, Descamps OS, et al.; European Atherosclerosis Society Consensus Panel. Familial hypercholesterolaemia is underdiagnosed and undertreated in the general population: guidance for clinicians to prevent coronary heart disease: consensus statement of the European Atherosclerosis Society. Eur Heart J. 2013 Dec;34(45):347890a.

12 Pang J, Martin AC, Mori TA, Beilin LJ, Watts GF. Prevalence of familial hypercholesterolemia in adolescents: potential value of universal screening? J Pediatr. 2016 Mar;170:315-6.

13 Wald DS, Bestwick JP, Morris JK, Whyte K, Jenkins L, Wald NJ. Child-parent familial hypercholesterolemia screening in primary care. N Engl J Med. 2016 Oct;375(17):1628-37.

14 Wiegman A, Gidding SS, Watts GF, Chapman MJ, Ginsberg HN, Cuchel M, et al.; European Atherosclerosis Society Consensus Panel. Familial hypercholesterolaemia in children and adolescents: gaining decades of life by optimizing detection and treatment. Eur Heart J. 2015 Sep;36(36):2425-37.

15 Australian Bureau of Statistics. 3101.0 - Australian Demographic Statistics, Jun 2017. Canberra: ABS; 2017

16 Hovingh GK, Davidson MH, Kastelein JJ, O'Connor AM. Diagnosis and treatment of familial hypercholesterolaemia. Eur Heart J. 2013 Apr;34(13):962-71.

17 Vlahos AP, Naka KK, Bechlioulis A, Theoharis $\mathrm{P}$, Vakalis $\mathrm{K}$, Moutzouri E, et al. Endothelial dysfunction, but not structural atherosclerosis, is evident early in children with heterozygous familial hypercholesterolemia. Pediatr Cardiol. 2014 Jan;35(1):63-70.

18 Watts G, Sullivan DR, Poplawksi N, van Bockxmeer F, Hamilton-Craig I, Clifton PM, O’Brien R, Bishop W, George P, et al. Familial hypercholesterolaemia: a model of care for Australasia. Atherosclerosis Supp 2011;12

19 Scientific Steering Committee on behalf of the Simon Broome Register Group. Risk of fatal coronary heart disease in familial hypercholesterolaemia. BMJ. 1991 Oct;303(6807):8936.

20 Versmissen J, Oosterveer DM, Yazdanpanah M, Defesche JC, Basart DC, Liem AH, et al. Efficacy of statins in familial hypercholesterolaemia: a long term cohort study. BMJ. 2008 Nov;337:a2423.

21 Bates TR, Burnett JR, van Bockxmeer FM, Hamilton S, Arnolda L, Watts GF. Detection of familial hypercholesterolaemia: a major treatment gap in preventative cardiology. Heart Lung Circ. 2008 Oct;17(5):411-3.

22 Marks D, Thorogood M, Neil HA, Humphries SE. A review on the diagnosis, natural history, and treatment of familial hypercholesterolaemia. Atherosclerosis. 2003 May; 168(1):1-14.

23 Umans-Eckenhausen MA, Defesche JC, Sijbrands EJ, Scheerder RL, Kastelein JJ. Review of first 5 years of screening for familial hypercholesterolaemia in the Netherlands. Lancet. 2001 Jan;357(9251):165-8.
24 Marks D, Thorogood M, Neil HA, Wonderling D, Humphries SE. Comparing costs and benefits over a 10 year period of strategies for familial hypercholesterolaemia screening. $J$ Public Health Med. 2003 Mar;25(1):47-52.

25 Minhas R, Humphries SE, Qureshi N, Neil HA; NICE Guideline Development Group. Controversies in familial hypercholesterolaemia: recommendations of the NICE Guideline Development Group for the identification and management of familial hypercholesterolaemia. Heart. 2009 Apr;95(7):584-7.

26 Marks D, Wonderling D, Thorogood $M$, Lambert H, Humphries SE, Neil HA. Cost effectiveness analysis of different approaches of screening for familial hypercholesterolaemia. BMJ. 2002 Jun;324(7349):1303.

27 Marang-van de Mheen PJ, ten Asbroek AH, Bonneux L, Bonsel GJ, Klazinga NS. Cost-effectiveness of a family and DNA based screening programme on familial hypercholesterolaemia in The Netherlands. Eur Heart J. 2002 Dec;23(24):1922-30.

28 Morris JK, Wald DS, Wald NJ. The evaluation of cascade testing for familial hypercholesterolemia. Am J Med Genet A. 2012 Jan;158A(1): 78-84.

29 Martin AC, Gidding SS, Wiegman A, Watts GF. Knowns and unknowns in the care of pediatric familial hypercholesterolemia. J Lipid Res. 2017 Sep;58(9):1765-76.

30 van Aalst-Cohen ES, Jansen AC, Tanck MW, Defesche JC, Trip MD, Lansberg PJ, et al. Diagnosing familial hypercholesterolaemia: the relevance of genetic testing. Eur Heart J. 2006 Sep;27(18):2240-6.

31 Wald DS, Bestwick JP, Wald NJ. Child-parent screening for familial hypercholesterolaemia: screening strategy based on a meta-analysis. BMJ. 2007 Sep;335(7620):599.

32 Klančar G, Grošelj U, Kovač J, Bratanič N, Bratina N, Trebušak Podkrajšek K, et al. Universal screening for familial hypercholesterolemia in children. J Am Coll Cardiol. 2015 Sep; 66(11):1250-7.

33 Wilson JM, Jungner G. Principles and practice of screening for disease: Public Health Papers. Geneva: World Health Organization; 1968.

34 Andermann A, Blancquaert I, Beauchamp S, Déry V. Revisiting Wilson and Jungner in the genomic age: a review of screening criteria over the past 40 years. Bull World Health Organ. 2008 Apr;86(4):317-9.

35 Burton H, Adams M, Bunton R, SchröderBäck P. Developing stakeholder involvement for introducing public health genomics into public policy. Public Health Genomics. 2009; 12(1):11-9.

36 Hodge JG Jr. Ethical issues concerning genetic testing and screening in public health. Am J Med Genet C Semin Med Genet. 2004 Feb; 125C(1):66-70.

37 Lemke AA, Harris-Wai JN. Stakeholder engagement in policy development: challenges and opportunities for human genomics. Genet Med. 2015 Dec;17(12):949-57.
38 Abelson J, Forest PG, Eyles J, Smith P, Martin E, Gauvin FP. Deliberations about deliberative methods: issues in the design and evaluation of public participation processes. Soc Sci Med. 2003 Jul;57(2):239-51.

39 Wald DS, Kasturiratne A, Godoy A, Ma L Bestwick JP, Brewer N, et al. Child-parent screening for familial hypercholesterolemia. J Pediatr. 2011 Nov;159(5):865-7.

40 Burgess MM. Public consultation in ethics: an experiment in representative ethics. J Bioeth Inq. 2004;1(1):4-13.

41 Tansey J, Burgess M. Democracy, ethics and genomics: introduction to a special issue. Integrated Assess. 2006;6:1-8.

42 Carman KL, Mallery C, Maurer M, Wang G, Garfinkel S, Yang M, et al. Effectiveness of public deliberation methods for gathering input on issues in healthcare: results from a randomized trial. Soc Sci Med. 2015 May;133: 11-20.

43 Degeling C, Carter SM, Rychetnik L. Which public and why deliberate? A scoping review of public deliberation in public health and health policy research. Soc Sci Med. 2015 Apr; 131:114-21.

44 Longo C, Rahimzadeh V, O'Doherty K, Bartlett G. Addressing ethical challenges at the intersection of pharmacogenomics and primary care using deliberative consultations. Pharmacogenomics. 2016 Nov; 17(16):1795805

45 Molster C, Maxwell S, Youngs L, Kyne G, Hope F, Dawkins H, et al. Blueprint for a deliberative public forum on biobanking policy: were theoretical principles achievable in practice? Health Expect. 2013 Jun;16(2):211-24.

46 Street J, Duszynski K, Krawczyk S, BraunackMayer A. The use of citizens' juries in health policy decision-making: a systematic review. Soc Sci Med. 2014 May;109:1-9.

47 Mosconi P, Castellani C, Villani W, Satolli R. Cystic fibrosis: to screen or not to screen? Involving a Citizens' jury in decisions on screening carrier. Health Expect. 2015 Dec;18(6): 1956-67.

48 Nicholls S, Wilson B, Craigie S, Etchegary HA. Public attitudes toward genomic risk profiling as a component of routine population screening. Genome. 2013;56:626-33.

49 Rychetnik L, Carter SM, Abelson J, Thornton $\mathrm{H}$, Barratt A, Entwistle VA, et al. Enhancing citizen engagement in cancer screening through deliberative democracy. J Natl Cancer Inst. 2013 Mar;105(6):380-6.

50 Hayeems RZ, Miller FA, Bombard Y, Avard D, Carroll J, Wilson B, et al. Expectations and values about expanded newborn screening: a public engagement study. Health Expect. 2015 Jun;18(3):419-29.

51 Goodin R, Dryzek J. Deliberative impacts: the macro-political uptake of mini-publics. Polit Soc. 2006;34:219-44.

52 Niemeyer S, Dryzek J. The ends of deliberation: meta-consensus and inter-subjective rationality as ideal outcomes. Schweiz Z Polit. 2007-08;2:497-526. 
53 Burgess M, O’Doherty K, Secko D. Biobanking in British Columbia: discussions of the future of personalized medicine through deliberative public engagement. Per Med. 2008 May;5(3):285-96.

54 Gastil J, Levine P. The deliberative democracy handbook: strategies for effective engagement in the 21st century. San Francisco: JosseyBass; 2005.

55 Delli Carpini M, Cook F, Jacobs L. Public deliberation, discursive participation and citizen engagement: a review of the empirical literature. Annu Rev Polit Sci. 2004;7:315-44.

56 DeSantes K, Dodge A, Eickhoff J, Peterson AL. Improving universal pediatric lipid screening. J Pediatr. 2017 Sep;188:87-90.

57 Langslet G, Ose L. Screening methods in the diagnosis and assessment of children and adolescents with familial hypercholesterolemia. Expert Rev Cardiovasc Ther. 2013 Aug;11(8): 1061-6.
58 National Heart, Lung, and Blood Institute. Expert panel on integrated guidelines for cardiovascular health and risk reduction in children and adolescents: summary report. Washington: US Department of Health and Human Services, National Institutes of Health; 2012.

59 Martin AC, Bell DA, Brett T, Watts GF. Beyond cascade screening: detection of familial hypercholesterolaemia at childhood immunization and other strategies. Curr Opin Lipidol. 2017 Aug;28(4):321-7.

60 de Ferranti SD, Daniels SR, Gillman M, Vernacchio L, PlutzkyJ, Baker AL. NHLBI Integrated Guidelines on Cardiovascular Disease Risk Reduction: can we clarify the controversy about cholesterol screening and treatment in childhood? Clin Chem. 2012 Dec;58(12):1626-30.

61 Gillman MW, Daniels SR. Is universal pediatric lipid screening justified? JAMA. 2012 Jan; 307(3):259-60.
62 Kusters DM, de Beaufort C, Widhalm K, Guardamagna O, Bratina N, Ose L, et al. Paediatric screening for hypercholesterolaemia in Europe. Arch Dis Child. 2012 Mar;97(3): 272-6.

63 Delatycki MB. The ethics of screening for disease. Pathology. 2012 Feb;44(2):63-8.

64 Standing Committee on Screening. Population Based Screening Framework. Canberra: AHMAC, Commonwealth of Australia; 2016.

65 Milne S, Sheeran P, Orbell S. Prediction and intervention in health-related behavior: a meta-analytic review of protection motivation theory. J Appl Soc Psychol. 2000;30:10643.

66 Hollands GJ, French DP, Griffin SJ, Prevost AT, Sutton S, King S, et al. The impact of communicating genetic risks of disease on riskreducing health behaviour: systematic review with meta-analysis. BMJ.2016 Mar;352:11102. 